\title{
Continuous monitoring of gas-phase species at trace levels with electrochemical detectors
}

\section{Part 2. Detection of chlorine and hydrogen chloride}

\author{
Wojciech Matuszewski ${ }^{1}$ and Mark E. Meyerhoff * \\ Department of Chemistry, University of Michigan, Ann Arbor, MI 48109 (USA)
}

(Recelved 18th December 1990)

\begin{abstract}
A detection system suitable for the contınuous and simultaneous measurement of gas-phase chlonne and hydrogen chloride in the low parts per billion $\left(10^{9}\right)$ by volume (ppbv) range is described Both gases are trapped through the walls of a microporous polypropylene tube into an appropriate flowing recipient buffer. The buffer then flows through two electrochemical detectors placed in series downstream from the sampling tube. Chloride 1ons from gas-phase hydrogen chloride are detected potentiometrically with an $\mathrm{Ag} / \Lambda \mathrm{gCl}$ workıng electrode Chlonne is detected biamperometrically (at $01 \mathrm{~V}$ ) via 1ts oxidation of added codide cons to form triodide. In a contınuous-flow measurement mode, detection of chlorine and hydrogen chloride at levels as low as 0.75 and $2.1 \mathrm{ppbv}$, respectively, is possible. Use of a 2-min stopped-flow/flow-injection arrangement results in a threc-fold improvement in detcetion limits The sclcetivity of each detector with respect to carbon dioxide, sulfur dıoxıde, nitrogen dioxıde and hydrogen sulfide is also examined
\end{abstract}

Keywords: Flow system, Amperometry; Potentiometry, Air, Chlorine, Gas detection; Hydrogen chloride

As described in Part 1 [1] and in a previous report [2], the use of long, narrow-bore, microporous polyethylene tubing (Celgard) as a sampling device in conjunction with flow-through electrochemical detectors provides a means of developing relatively simple systems for the continuous monitoring of gases at trace levels. Although these two previous efforts were focused on the measurement of a single species, it should also be possible to incorporate multiple electrochemical detectors in series downstream from the sampling device. This approach would permit the contınuous measurement of several gas-phase species simultaneously. This paper describes the development and analyti-

\footnotetext{
${ }^{1}$ On leave from Department of Chemıstry, Unuversity of Warsaw, Warsaw, Poland.
}

cal performance of such an arrangement for the detection of chlorine and hydrogen chloride.

Chlorine and hydrogen chloride are normally present at low levels in the atmosphere [3-5] and a variety of methods devised to measure these species generally require long sampling periods and/or complex instrumentation to achieve the necessary detection limits [6,7]. The system described here utilizes a potentiometric $\mathrm{Ag} / \mathrm{AgCl}$ wire electrode and twin polarized platinum electrodes to detect hydrogen chloride and chlorine, respectively. The flow manifold employed is illustrated in Fig. 1. Hydrogen chloride in the gas phase surrounding the microporous tubing dissolves in a slightly basic recipient buffer which flows through the sampling tube. The chloride ions formed from this dissolution are detected by the $\mathrm{Ag} / \mathrm{AgCl}$ electrode. The recipient buffer stream is then merged with a 


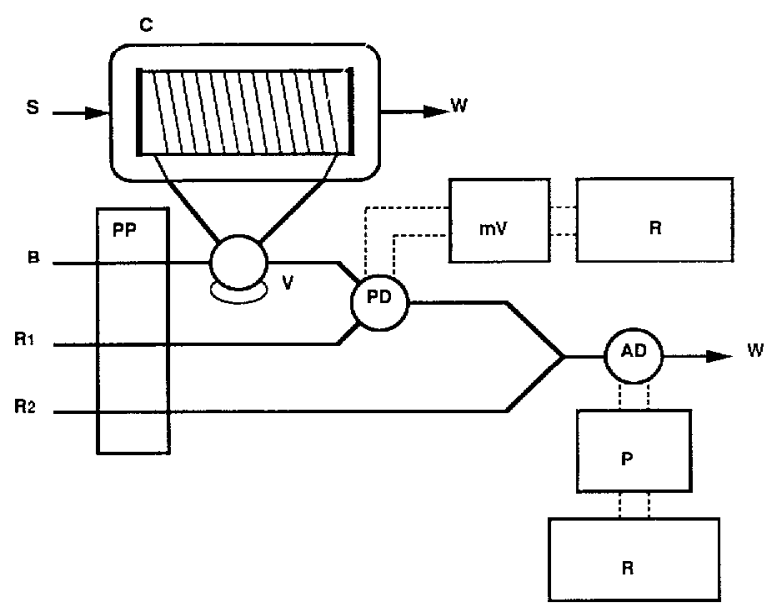

Fig 1 Schematic diagram of manifold used for contınuous-flow and stopped-flow detection of gas-phase chlorine and hydrogen chloride $\mathrm{S}=$ Analyte gas in background of nitrogen and air; $C=$ glass chamber with coiled Celgard tubing; $W=$ waste, $P P=$ peristaltic pump, $B=$ recipient buffer, $R_{1}=1 \mathrm{mM} \mathrm{KCl}$ in acetate buffer; $\mathbf{R}_{2}=002 \mathrm{M}$ potassium lodide; $\mathrm{V}=$ six-port rotary injection valve; $\mathrm{PD}=\mathrm{Ag} / \mathrm{AgCl}$ potentiometric detector with reference, $\mathrm{AD}=$ twin polanzed $\mathrm{Pt} / \mathrm{Pt}$ biamperometric detector, $\mathrm{MV}=\mathrm{mV}$ meter, $\mathrm{R}=$ strip-chart recorder, $\mathbf{P}=$ potentiostat.

stream containing excess iodide. Free chloride present reacts with iodide in accordance with the following redox reaction:

$\mathrm{Cl}_{2}+3 \mathrm{I}^{-} \rightarrow 2 \mathrm{Cl}^{-}+\mathrm{I}_{3}^{-}$

The presence of truodide depolarizes the cathode of twin polarized micro-platınum electrodes, resultıng in an increase in current. This biamperometric method has been utilized previously to detect dissolved levels of chlorine [9].

\section{EXPERIMENTAL}

\section{Apparatus}

The manifold used for all gas-phase measurements is shown in Fig. 1. A 200-cm length of Celgard tubing (see Part 1 [1]) was employed as a sample loop for a Rheodyne (Cosatı, CA) six-port PTFE rotary injection valve. This loop was placed in a glass chamber for characterizing the gas-phase response of the system [1,2]. Solutions were pumped through the system with a Rainin (Woburn, MA) Rabbit perıstaltic pump. Two
$\mathrm{Ag} / \mathrm{AgCl}$ electrodes served as the potentiometric detector for hydrogen chloride measurements. The electrodes were prepared by inserting polished picecs of silver wire $(0.3 \mathrm{~mm}$ diameter, $5 \mathrm{~mm}$ long) in a solution of $3 \mathrm{M}$ iron(III)chloride in dilute hydrochloric acid $(1+3)$ for $30 \mathrm{~min}$. One $\mathrm{Ag} / \mathrm{AgCl}$ electrode served as the reference. $\mathrm{A}$ solution of $1 \mathrm{mM} \mathrm{KCl}$ in $0.1 \mathrm{M}$ acetic acid served as the reference electrolyte stream $\left(R_{1}\right)$ for the potentiometric signals. These signals were measured with a Fisher Scientific (Romulus, MI) Model $620 \mathrm{pH} / \mathrm{mV}$ meter and recorded on a Fisher Recordall Series 5000 strip-chart recorder.

$\Lambda$ biamperometric flow cell with two platinum wire electrodes was the same as that described previously $[8,9]$. The electrodes were connected to a laboratory-made potentiostat and polarized at $100 \mathrm{mV}$. Current outputs were recorded on a Linear Instruments (Irvine, CA) strip-chart recorder.

\section{Reagents and gas standards}

All chemicals were of analytical-reagent grade. For most simultaneous chlorine and hydrogen chloride measurements, a $0.01 \mathrm{M}$ borate buffer (pH 9.0) served as the recipient solution flowing through the Celgard tubing. This buffer was prepared by dissolving $3.8 \mathrm{~g}$ of sodium tetraborate in 11 of deionized water and adjusting the $\mathrm{pH}$ to 9.0 with concentrated nitric acid All other solutions were prepared by dissolving appropriate amounts of reagent salts in deionized water.

Two methods were employed to generate gasphase standards withın the glass chamber surrounding the Celgard sampling tube (see Fig. 2). In some instances, diluent air that had been passed through a charcoal column $(3 \mathrm{~cm}$ diameter, $30 \mathrm{~cm}$ long) was mixed with commercially available gas mixtures [e.g., 52 ppmv $\mathrm{Cl}_{2}$ in $\mathrm{N}_{2}$ from Matheson (Chicago, IL)] in appropriate proportions via volumetric flow control valves. Alternatively, the diluent air was mixed in suitable volumetric ratios with the output from a laboratory-made permeation tube The permeation tube was constructed as described in Part 1 [1] and $\mathrm{N}_{2}$ was used as the diluent gas. Hydrogen chloride standards were generated by passing $24 \%(\mathrm{w} / \mathrm{w})$ hydrochloric acid through the inner microporous PTFE tube (Gore- 


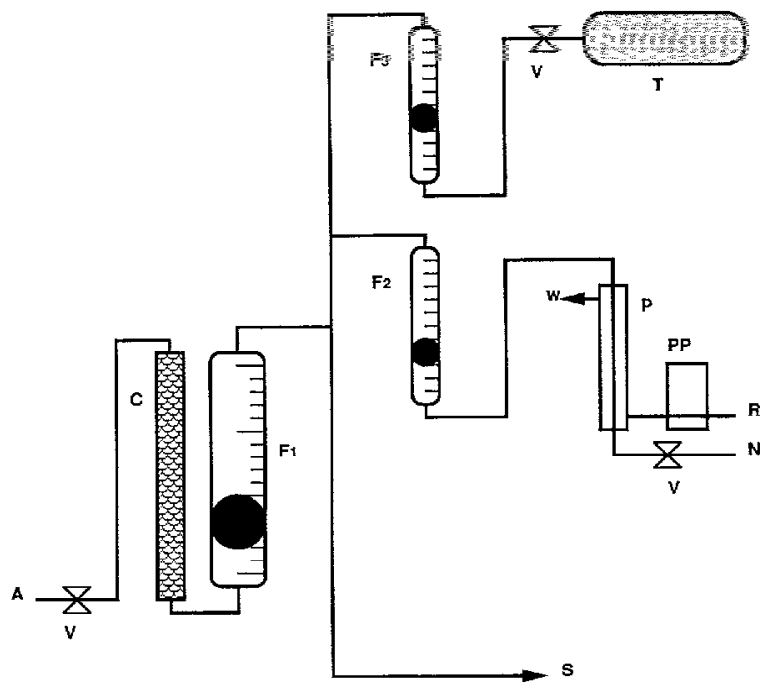

Fig 2. Arrangement used to generate simultaneous chlorine and hydrogen chloride gas-phase standards $\mathrm{A}=$ Air stream, $\mathrm{N}=$ nitrogen stream, $\mathrm{T}=$ commercial tank of 52 ppmv chlorine in nitrogen; $\mathrm{V}=$ valves; $\mathrm{F}_{1}-\mathrm{F}_{3}=$ flow-meters; $\mathrm{P}=$ microporous permeation tube; $P P=$ peristaltic pump, $\mathbf{R}=$ solution of concentrated hydrochloric ac1d; $\mathrm{W}=$ waste, $\mathrm{S}=$ gas sample stream flowing into glass chamber

Tex). At a given flow-rate of $\mathrm{N}_{2}$ diluent, the concentration of hydrogen chloride gas leaving the permeation tube was determined by using a conventional gas scrubber arrangement, in which the $\mathrm{HCl}-\mathrm{N}_{2}$ stream was bubbled into a volume of $0.01 \mathrm{M} \mathrm{NaOH}$. After a fixed time, the concentration of chloride in the $\mathrm{NaOH}$ solution was determined by direct potentiometry with an $\mathrm{Ag} /$ $\mathrm{AgCl}$ working electrode. Nitrogen dioxıde was generated in the permeation tube by using a solution of $0.125 \mathrm{M} \mathrm{NaNO}$, in $0.1 \mathrm{M} \mathrm{H}_{2} \mathrm{SO}_{4}$ as the donor solution. The concentration of gas-phase nitrogen dioxide generated in the $\mathrm{N}_{2}$ recipient stream was determined by a modified version of the Griess spectrophotometric method [10]. Similarly, sulfur dioxide and hydrogen sulfide were generated within the permeation tube by using acidified $\mathrm{Na}_{2} \mathrm{SO}_{3}$ and $\mathrm{Na}_{2} \mathrm{~S}$ solutions, respeclively. The concentrations of gas-phase sulfur d1oxide and hydrogen sulfide were determined (after scrubbing a given volume in base) by addition of potassium rodide and back-titration of any excess iodide with sodium thosulfate [11].

\section{RESUETS AND DISCUSSION}

\section{Optimization of measurement conditions}

The experimental arrangement shown in Fig. 1 can be used to detect a single gas (either hydrogen chloride or chlorine), or both species simultaneously. When detecting hydrogen chloride alone, the potassium lodide reagent stream $\left(R_{2}\right)$ and the biamperometric detector can be eliminated from the system. When measuring only chlorine, the potentiometric $\mathrm{Ag} / \mathrm{AgCl}$ detector can be removed and $\mathrm{KCl}$ can be eliminated from reagent stream $\mathbf{R}_{1}$ (the acetic acid stream is still required to optimize subsequent reaction of chlorine and lodide; see below). Such single-component detection systems were employed in prelimınary studies to characterize fully each gas-phase detection arrangement and to optimize the compositions of the required flowing reagents.

For detection of both chlorne and hydrogen chloride, the same recipient buffer must be used for the collection of these species. A wide variety of recipient solutions were evaluated in terms of signal quality (i.e., sensitivity, stability, return to baselıne, etc.) for each detector. Figure 3 illustrates the effect of recipient solution $\mathrm{pH}$ on the sensitivity of each detector. A $0.01 \mathrm{M}$ borate buffer (pH 90 ) yielded the optimum signal for hydrogen chloride measurements with the $\mathrm{Ag} / \mathrm{AgCl}$ potentiometric detector. Increasing the $\mathrm{pH}$ decreased the potentiometric response to gas-phase hydrogen chloride and, at the same time, caused the

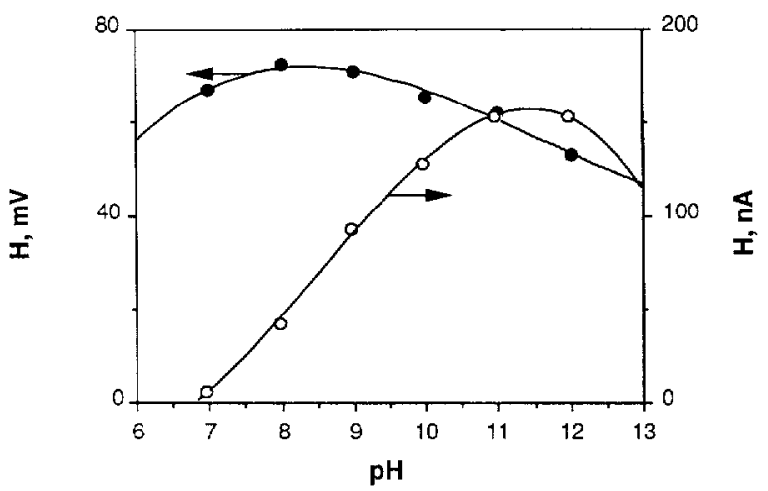

Fig. 3 Effect of recipient buffer $\mathrm{pH}$ on the observed gas-phase response to (o) 112 ppbv chlorine and (ब) $276 \mathrm{ppbv}$ hydrogen chloride 
$\mathrm{Ag} / \mathrm{AgCl}$ detector to have a slower response time toward step changes in the hydrogen chloride levels. These two effects may be due to the formation of $\mathrm{Ag} / \mathrm{AgOH}\left(K_{\mathrm{sp}}=1 \times 10^{-8}\right)$ at these higher $\mathrm{pH}$ values. The optimum response of the amperometric detector toward chlorine was observed when the $\mathrm{pH}$ of the recipient stream was $>11$. This is due to the greater trapping efficiency of chlorine gas at such high pII. Indeed, the hydrolysis reaction of chlorine may be written as follows:

$\mathrm{Cl}_{2}+\mathrm{H}_{2} \mathrm{O} \cdot 2 \mathrm{H}^{+}+\mathrm{ClO}^{-}+\mathrm{Cl}^{-}$

Therefore, collection of chlorine gas through the walls of the Celgard sampling tube is cnhanced at high $\mathrm{pH}$ (see Fig. 3). However, the quantitative redox reaction of chlorine with iodide (reaction 1 ), necessary for the biamperometric detector, is favored at low $\mathrm{pH}$, as dissolved chlorine gas is required for this reaction and the triiodide product is more stable under such conditions. Hence, the $\mathrm{pH}$ of the recipient solution must be decreased downstream from the sampling tube before reacting the chlorine with iodide. This was accomplished with acetic acid (see Fig. 1).

From Fig. 3, it is clear that the optimum recipient solution $\mathrm{pH}$ for each detector differs. A compromise must therefore be made in terms of detection limits for at least one of the gases. As it was found that the biamperometric detector provided lower detection limits for chlorine than the potentiometric electrode for hydrogen chloride, subsequent experiments were carried out using the $0.01 \mathrm{M}$ borate buffer ( $\mathrm{pH} 9.0$ ) as the recipient solution flowing through the Celgard collection tube. Under such conditions, ca. 50\% of the max1mum signal was observed for the biamperometric detection of gas-phase chlorine.

The total flow-rate of gas past the Celgard collection tubing was also found to influence the sensitivity of each detector. Figure 4 illustrates the effect of total gas flow-rate (from 7.65 to 30.61 $\min ^{-1}$ ) on the continuous current output of the chlorine detector. Increasing the flow-rate increases the sensitivity of the system significantly. Similar results were observed for the potentiometric detection of hydrogen chloride (see Fig. 5). This effect appears to be due to the fact that mass transfer of the analyte gases through the walls of
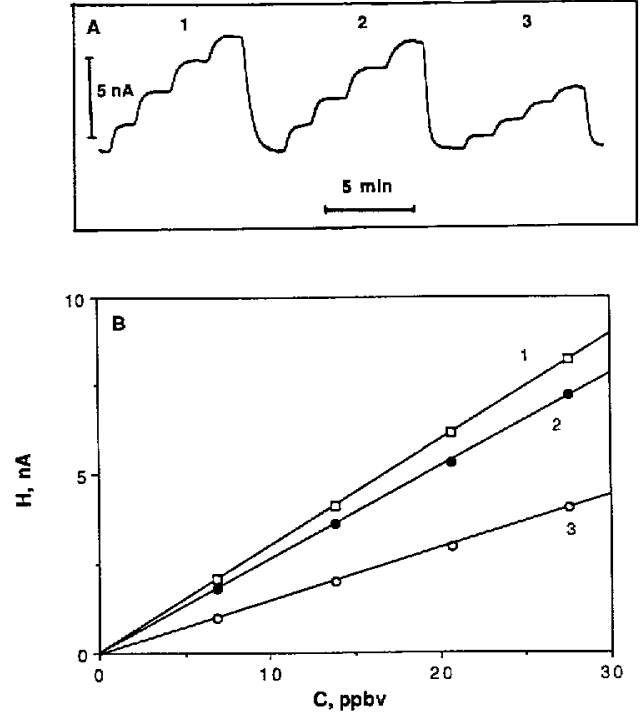

F1g. 4. Effect of total gas sample flow-rate on the response of the chlorine detector $(\Lambda)$ Direct strip-chart response, $(B)$ resulting calibration graphs (1) $30.61 \mathrm{~min}^{-1}$ ( $\mathrm{nA}=0.298\left[\mathrm{Cl}_{2}\right]$ $+0.0015, r^{2}=0$ 999), (2) $1531 \mathrm{~min}^{-1}\left(\mathrm{nA}=0.260\left[\mathrm{Cl}_{2}\right]+\right.$ $\left.00001, r^{2}=0.999\right)$, (3) $7.651 \mathrm{~min}^{-1} \quad(\mathrm{nA}=0147 \pm 00499$, $r^{2}=0999$ ).

the Celgard tubing is limited by a thin stagnant layer of recipient solution retained some distance into the walls of the porous tubing (see Fig. 6). On

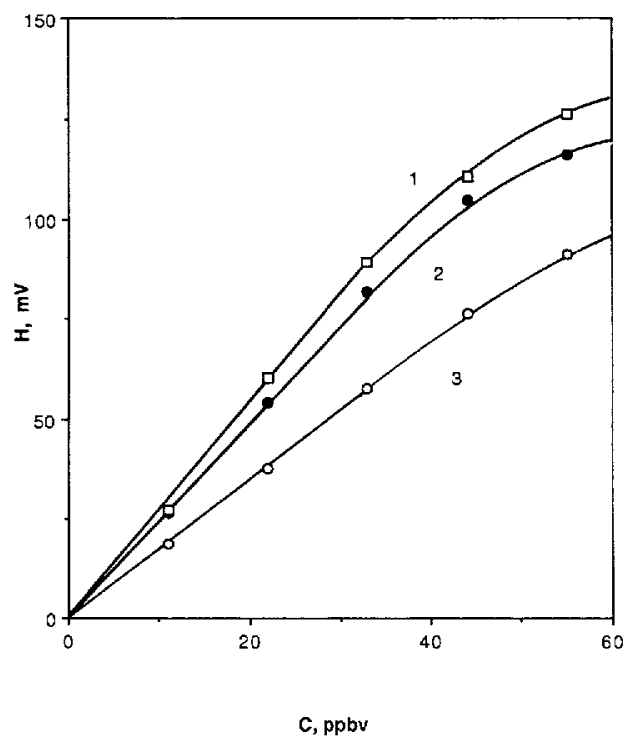

F1g. 5 Effect of total gas sample flow-rate on the response of the hydrogen chlonde detector (1) 306 , (2) 153 , (3) 7651 $\mathrm{min}^{-1}$ 


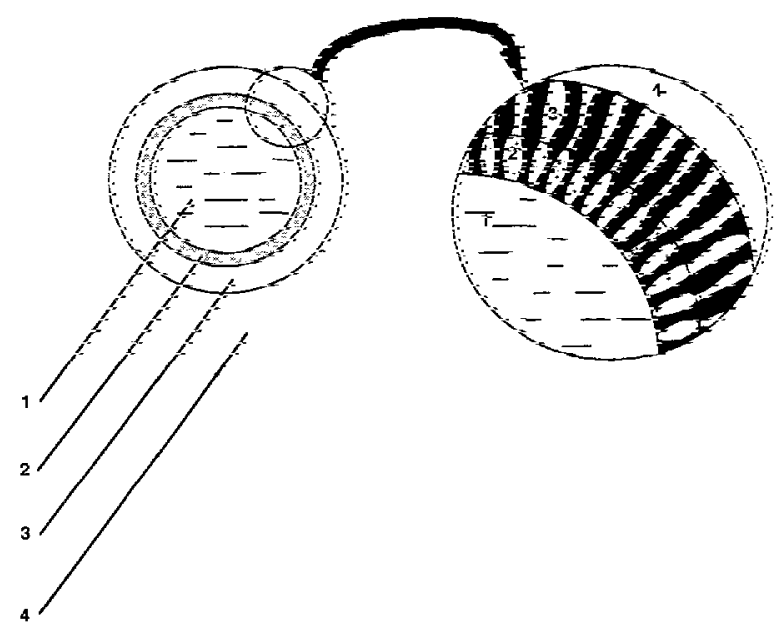

Fig 6. Schematic dagrain of Celyard tubing wall and expanded view of stagnant liquid layer withın porous structure. $1=$ Recipient buffer inside gas-permeable tubing, 2 = "stagnant" layer of the buffer in membrane structure; $3=$ layer of the air in the membrane structure; $4=$ outer gas medium.

either side of this stagnent solution layer, high gas-phase diffusion coefficients and effective convective mixing caused by the flow of the recipient stream solution eliminate the possibility of forming significant concentration gradients. However, at high gas flow-rates, evaporation of recipient solution is enhanced, and this can cause a decrease in the steady-state thickness of the stagnant layer. This may result in greater mass transport of the gas into the flowing recipient solution.

Preliminary experiments were done to examine this hypothesis. The actual flow-rate of recipient solution and the mass of the entire Celgard collec-

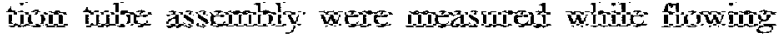
art past the tore at dferent total tow-iates. Fable 1: sumparizes the results of ths study. Fea be seer that the drfereme in the bot fow rate

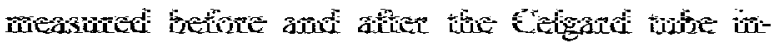
creases at higher flow-rates owng to evaporation.

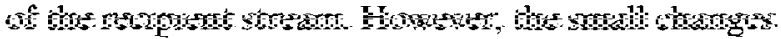

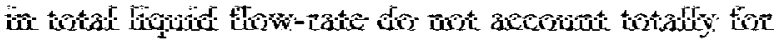
the much larger changes in gas sensitivity observed, in this instance for the hydrogen chloride detection system. Therefore, aside from evaporation causing an effective increase in dissolved gas concentrations in the recipient stream, evaporation must also play a rolc in controlling the steady-state thickness of the liquid layer trapped within the walls of the porous tubing. This is further confirmed by the observed decrease in mass of the Celgard tubing at increasing flow-rates of air.

When the gas-phase flow-rate is held constant, reproducible responses to both hydrogen chloride and chlorine can be achieved using the arrangement shown in Fig. 1. Figure 7 illustrates the typical responses of both detectors when levels of hydrogen chloride and chlorine were varied in the gas-phase stream. Note that the chlorine detector exhibits no response to hydrogen chloride; however, the potentiometric hydrogen chloride detector does respond to chlorine. This is due to the formation of chloride 1ons from the trapped chlorine gas as depicted in reaction 2. In practice, for true simultaneous detection of both gases, errors due to chlorine interference can be corrected by prior evaluation of the sensitıvity of the hydrogen chloride detector toward chlorine and a knowl-

\section{TABLE 1}

Effect of aur flow-rate on volumetric flow of recipient buffer, mass of Celgard collection tube and $\mathrm{HCl}$ detector sensitivity

\begin{tabular}{|c|c|c|c|c|}
\hline $\begin{array}{l}\text { Volumetric air flow-rate } \\
\left(1 \mathrm{~min}^{-1}\right)\end{array}$ & $\begin{array}{l}\text { Linear aur flow-rate } \\
\left(\mathrm{cm} \mathrm{s}^{-1}\right)\end{array}$ & $\begin{array}{l}\text { Difference between } \\
\text { inlet and outlet flows } \\
\text { of recipient buffer } \\
\left.(\mathrm{ml} \mathrm{min})^{-1}\right)^{d}\end{array}$ & $\begin{array}{l}\text { Decrease in mass } \\
\text { of Celgard tube } \\
(\mathrm{mg})\end{array}$ & $\begin{array}{l}\text { Sensitivity of } \mathrm{Ag} / \mathrm{AgCl} \\
\text { electrode } \\
\text { response to } \mathrm{HCl} \\
{\left[\mathrm{mV}(\mathrm{ppb} v \mathrm{HCl})^{-1}\right]}\end{array}$ \\
\hline 30.6 & 289 & $022(10.5 \%)$ & $107 \pm 03$ & 1294 \\
\hline 153 & 1445 & $0.19(89 \%)$ & $7.6 \pm 0.3$ & 1078 \\
\hline 765 & 0.723 & $0.12(59 \%)$ & $1.2 \pm 0.3$ & 0808 \\
\hline
\end{tabular}

\footnotetext{
${ }^{a}$ Recipient buffer flow-rate $=20 \mathrm{ml} \mathrm{\textrm {min } ^ { - 1 }}$
} 


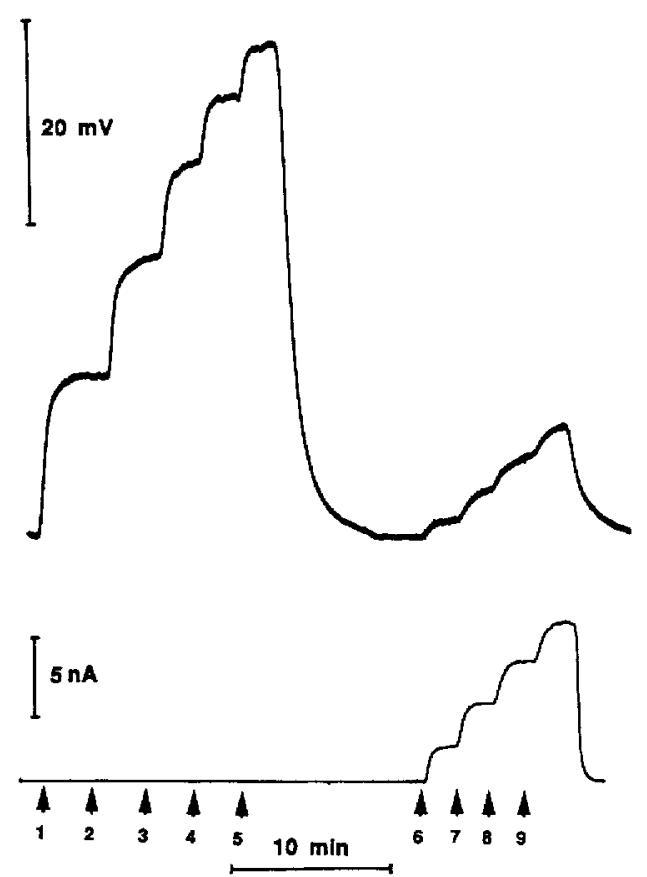

Fig 7 Typical signal output for potentiometric (upper) and biamperometric (lower) detectors in response to different levels of chlorine and hydrogen chloride gas, respectively Arrows denote change in sample stream gas (1) 21.2 , (2) 42.4 , (3) 636 (4) 84.8, (5) 105 ppbv hydrogen chloride; (6) 67 , (7) 13.3, (8) 201 , (9) 267 ppbv chlorine

edge of the existing chlorine levels from the more selective biamperometric signal.

It is important to note that the detection of hydrogen chloride is based on potentiometry, which inherently displays a logarithmic response. However, over a very narrow and low concentra- tion range of the detected ion (in this instance chloride), such sensors will display nearly linear responses [12]. In this instance, over a wider range of gas-phase hydrogen chloride levels $(0-100$ ppbv), plots of potent1ometric response vs. gas concentration exhibited the expected non-linear behavior (see Fig. 5), whereas the response of the biamperometric chlorine detector remained linear (see Fig. 4).

\section{Selectivity}

The selectivity of both detection systems with respect to potential interference from nitrogen $d_{1}$ oxıde, carbon dioxide, sulfur dioxide and hydrogen sulfide was examined. Such studies were done by noting the change in detector signals when given levels of these gases were introduced into an air stream containing 10.6 ppbv hydrogen chloride and 45.6 ppbv chlorine. Table 2 shows the results. Neither nitrogen dioxide or carbon dioxide at levels in excess of the analyte gases yielded any change in response for both detectors. The presence of sulfur dioxide and hydrogen sulfide produced significant positive response on the hydrogen chloride detector (due to the response of the $\mathrm{Ag} / \mathrm{AgCl}$ electrode to sufite and sulfide ions) and negative interferences on the chlorine detector (due to reaction of sulfite and sulfide ions with triiodide). To help reduce such effects, the air sample stream was first passed through a column packed with chromium trioxide particles, which has been ut1lized previously to remove such species from gaseous samples [13]. However, only when the

TABLE 2

Effect of various gases on the responses of chlorine and hydrogen chlonde detection system ${ }^{a}$

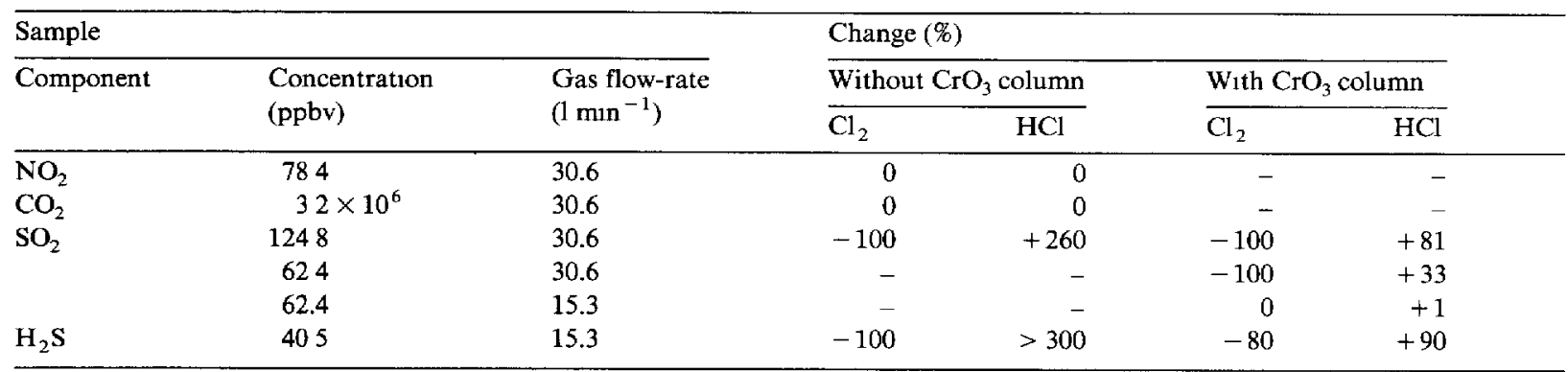

\footnotetext{
${ }^{a}$ In the presence of a constant 106 ppbv hydrogen chloride and 456 ppbv chlonne
} 
total sample flow-rate was reduced to $15.31 \mathrm{~min}^{-1}$ did the interference from sulfur dioxide disappear (see Table 2). The chromium trioxide column was relativcly ineffective at removing the hydrogen sulfide interference even at this lower total arr flow-rate.

In preliminary experiments, some enhancement in selectıvity of the hydrogen chloride detection system over hydrogen sulfide was achieved by using a metalloporphyrin-based polymer membrane-type chloride ion-selective electrode as the detector [14]. Such an electrode exhibits a much lower response to sulfıde ions than a $\mathrm{Ag} / \mathrm{AgCl}$ electrode. However, the responses to hydrogencarbonate and sulfite ions with the polymer membrane electrode are greater than those observed with the $\mathrm{Ag} / \mathrm{AgCl}$ electrode, and thus gasphase selectivity over carbon dioxide and sulfur dioxide is compromised by using this new 1onselective electrode in place of the $\mathrm{Ag} / \mathrm{AgCl}$ working electrode.

\section{Stopped-flow / flow-injection measurements}

As described previously for hydrogen peroxide measurements [1], if the recipient buffer stream is stopped for a short period within the Celgard collection tube and then allowed to flow through the detectors in a flow-injection manner, a significant enhancement in the sensitivity to both chlorine and hydrogen chloride can be achieved. The enhancement in signal is linearly related to the stopped-flow time, until the time at which the recipient solution approaches equilibrium with the gas phase (in terms of partial pressure of analyte gas). This is illustrated in Fig. 8 for the chlorine detector. Note that the output of such an experiment yields a transient flow-1njection analysis-type peak signal followed by the the same steady-state detection signal observed when the recipient buffer is allowed to flow continuously (Fig. 8A). At a fixed trapping tıme (e.g., $2 \mathrm{~min}$ ), the peak response is linearly related to the concentration of chlorine gas surrounding the Celgard collection tube (see Fig. 9). Based on the slope of the calibration graph from the stopped-flow data \{e.g., peak height vs. chlorine concentration as shown in Fig. 9: $\mathrm{nA}=1.48\left[\mathrm{Cl}_{2}\right]+1.07, r^{2}=0.999$, s.d.,$=0.045$ nA, s.d ${ }_{x}=0.090$ ppbv), a nearly three fold en-
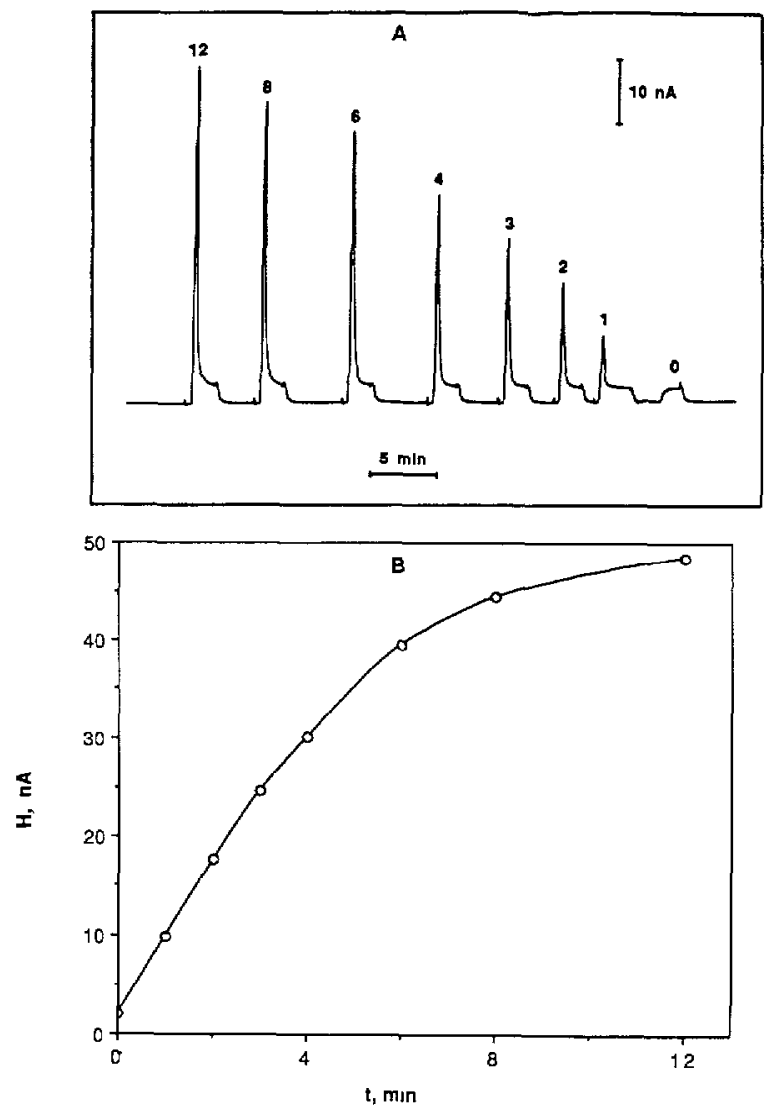

Fig 8 Effect of stopped-flow time on the amperometric signal observed for 85 ppbv chlorine. (A) Strip-chart recording of signals; (B) plot of peak signal as a function of stopped-flow time

hancement in sensitivity is observed in comparison with the continuous-flow mode\}. Similar cnhancements in sensitivity were observed when the stopped-flow concept was utilized in conjunction with the hydrogen chloride measurement system (not shown).

In summary, relatively simple electrochcmical detection systems suitable for the continuous monitoring of gas-phase chlorine and hydrogen chloride have been described. The use of a microporous narrow-bore collection tube permits the continuous measurement of these species at levels as low as 0.75 and $2.1 \mathrm{ppbv}$, respectively Further enhancement in sensitivity can readily be achieved by using a stopped-flow approach. Although certain gases (particularly hydrogen sulfide) can in- 


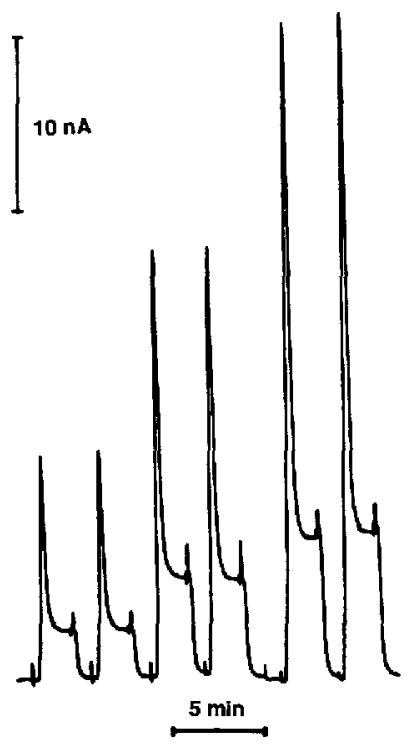

Fig 9 Typical output of chlorine detcetor at $84,16.8$ and 25.2 ppbv $\mathrm{Cl}_{2}$ using $2-\mathrm{min}$ stopped-flow measurement mode

terfere when in excess, the overall simplicity and sensitivity of the proposed detection schemes should allow the use of this sensing system in specific industrial process monitoring applications (e.g., incinerators and headspace of solution reactions) where the level of potential interferent gases would be low or could be reduced by appropriate scrubbing.

This work was partially supported by Mallinckrodt Sensor Systems and the Office of the Vice President for Research at the University of Michıgan.

\section{REFERENCES}

1 W Matuszewski and M E Meyerhoff, Anal Chım. Acta, 248 (1991) 379

2 D M Pranitıs and M.E Meyerhoff, Anal. Chem, 59 (1987) 2345

3 U.S. Public Health Service, Compilation of Air Pollution Factors, US-PHS 999-AP-42, Public Health Services, Bethesda, MD, 1968

4 B M. McCormuck, Introduction to the Scientific Study of Atmosphenc Pollution, Reidel, Dordrecht, 1971.

5 P O. Warner, Analysis of Air Pollutants, Wlley, New York, 1976

6 R M. Harrison and R Perry (Eds), Handbook of Air Pollution Analysis, Chapman and Hall, London, 2nd edn, 1986

7 S. Calvert and H M Englund (Eds), Handbook of Air Pollution Technology, Wiley, New York, 1984

8 A Hulanıckı, W Matuszewskı and M Trojanowicz, Anal Chım Acta, 194 (1987) 119

9 W Matuszewskı and M. Trojanowicz, Anal Chım Acta, 207 (1988) 59

$10 \mathrm{Z}$ Marczenko, Spectrophotometric Determination of Elements, Horwood, Chichester, 1986

11 M Katz, Anal. Chem , 22 (1950) 1040

$12 \mathrm{M}$ Trojanowicz and $\mathrm{W}$ Matuszewskı, Anal Chım. Acta, 138 (1982) 71

13 B.E. Saltzman, A F. Wartburg and R A. Taft, Anal Chem, 37 (1965) 779

14 M E Meyerhoff, S.B Park, H S Yım and GS Cha, in M F Burritt and R F Moran (Eds.), Proceedings of Symposium on Methodology and Clinical Application of Electrochemical and Fiber Optic Sensors, Amencan Associatıon for Clinical Chemistry, Washington, DC, 1990 , pp 65-88. 